\title{
Rational design of nonstoichiometric bioceramic scaffolds via digital light processing: tuning chemical composition and pore geometry evaluation
}

Yifan $\mathrm{Li}^{1 \dagger}$, Ronghuan $\mathrm{Wu}^{1 \dagger}$, Li Y Y ${ }^{2}$, Miaoda Shen ${ }^{1}$, Xiaoquan Ding ${ }^{1}$, Fengling Lu ${ }^{3}$, Mengtao Liu ${ }^{3}$, Xianyan Yang ${ }^{3}$, Zhongru Gou ${ }^{3 *}$ and Sanzhong $X u^{1 *}$ (D)

\begin{abstract}
Bioactive ceramics are promising candidates as 3D porous substrates for bone repair in bone regenerative medicine. However, they are often inefficient in clinical applications due to mismatching mechanical properties and compromised biological performances. Herein, the additional $\mathrm{Sr}$ dopant is hypothesized to readily adjust the mechanical and biodegradable properties of the dilute Mg-doped wollastonite bioceramic scaffolds with different pore geometries (cylindrical-, cubic-, gyroid-) by ceramic stereolithography. The results indicate that the compressive strength of $\mathrm{Mg} / \mathrm{Sr}$ co-doped bioceramic scaffolds could be tuned simultaneously by the Sr dopant and pore geometry. The cylindrical-pore scaffolds exhibit strength decay with increasing Sr content, whereas the gyroidpore scaffolds show increasing strength and Young's modulus as the Sr concentration is increased from 0 to 5\%. The ion release could also be adjusted by pore geometry in Tris buffer, and the high Sr content may trigger a faster scaffold bio-dissolution. These results demonstrate that the mechanical strengths of the bioceramic scaffolds can be controlled from the point at which their porous structures are designed. Moreover, scaffold bio-dissolution can be tuned by pore geometry and doping foreign ions. It is reasonable to consider the nonstoichiometric bioceramic scaffolds are promising for bone regeneration, especially when dealing with pathological bone defects.
\end{abstract}

Keywords: Pore geometry, Mechanical properties, Biodegradation, Nonstoichiometric wollastonite scaffolds, Ceramic stereolithography

\footnotetext{
* Correspondence: zhrgou@zju.edu.cn; xusanzhong@zju.edu.cn

${ }^{\dagger}$ Yifan Li and Ronghuan Wu are co-first author.

${ }^{3}$ Bio-nanomaterials and Regenerative Medicine Research Division,

Zhejiang-California International Nanosystem Institute, Zhejiang University, \#866 Yuhangtang Road, Hangzhou, Zhejiang Province 310058, P. R. China 'Department of Orthopedics, the First Affiliated Hospital, Zhejiang University

School of Medicine, \#79 Qingchun Road, Hangzhou, Zhejiang Province

310003, P. R. China

Full list of author information is available at the end of the article
}

C C The Author(s). 2021 Open Access This article is licensed under a Creative Commons Attribution 4.0 International License, which permits use, sharing, adaptation, distribution and reproduction in any medium or format, as long as you give appropriate credit to the original author(s) and the source, provide a link to the Creative Commons licence, and indicate if changes were made. The images or other third party material in this article are included in the article's Creative Commons licence, unless indicated otherwise in a credit line to the material. If material is not included in the article's Creative Commons licence and your intended use is not permitted by statutory regulation or exceeds the permitted use, you will need to obtain permission directly from the copyright holder. To view a copy of this licence, visit http://creativecommons.org/licenses/by/4.0/ The Creative Commons Public Domain Dedication waiver (http://creativecommons.org/publicdomain/zero/1.0/) applies to the data made available in this article, unless otherwise stated in a credit line to the data. 


\section{Introduction}

The treatment of bone defects is currently a difficult orthopedic challenge and a large number of investigations have focused on it. A method to improve the osteogenesis of bone grafts and reductions in the amounts of autologous bone required is urgently required [1-3]. Therefore, the development of artificial, biodegradable bone-repair biomaterials, with mechanical properties that match the rate of new bone growth, is a valuable pursuit [4]. Additive manufacturing technology has promoted the research and development of bone regeneration $[5,6]$. The most promising additive manufacturing techniques include three-dimensional (3D) printing, fused deposition modeling, selective laser sintering, stereolithography and so on [7-10]. Among the most important characteristics of the biomaterials created is their morphology, including pore shape, pore connectivity, and overall porosity $[11,12]$. These factors play an important role in the process of bone regeneration. The three-dimensional (3D) porous structure should provide the necessary mechanical support for cells to proliferate and maintain their differential function and restore the initial shape of new bone [13]. Nowadays, Macroporous scaffolds with arbitrary internal structure and external morphology can be realized using the combination of computer-aided design (CAD) and layer-by-layer printing [14]. Meanwhile, the pore geometry and shape of the bioceramic scaffolds prepared by stereolithography can be accurately controlled to match the arbitrary and complex 3D anatomical shape of the bone defect $[15,16]$.

Wollastonite $\left(\mathrm{CaSiO}_{3} ; \mathrm{CSi}\right)$ is a promising bioceramic candidate with good biocompatibility and biodegradability [17]. It has been demonstrated that CSi bioceramic can enhance bone regeneration and vascularization in vitro and in vivo by releasing calcium and silicon ions into the surrounding environment [18]. Moreover, its excellent apatite mineralization ability may contribute to its biological activity and promote osteogenesis in vivo [19]. However, pure CSi alone cannot be used as bone substitutes for load-bearing bone, due to the inherent shortcomings of high biodegradation rate and poor sintering property, which result in fast ion release, collapse of porous architecture, as well as poor mechanical support [20, 21]. Because of these limitations, researchers have been widely exploring new strategies to optimize the biodegradation rate and mechanical properties of CSi bioceramics [22]. One important strategy is the addition of therapeutic ions and bioactive substances to CSi bioceramics that optimize their degradation rates, improve their mechanical properties, and promote the repair of bone defects, especially in patients with basic pathological diseases such as osteoporosis [22-25].
Strontium ( $\mathrm{Sr}$ ) is the well-known, biologically active essential element in bone metabolism. It improves bone mineral density and anti-absorption in human bone tissue [26-28]. It was previously reported that Sr-doping in Ca-phosphate and Ca-silicate bioceramics may accelerate their bio-dissolution in vitro [23, 24]. Furthermore, when integrated into biomaterials, $\mathrm{Sr}$ can be administered directly into specific bone defects, which greatly reduces the necessary drug dosage and the risk of possible side effects $[29,30]$. It is well-known that $\mathrm{Sr}$ can stimulate osteoblasts and inhibit osteoclasts in vitro, while magnesium $(\mathrm{Mg})$ is important to bone metabolism, stimulates new bone formation, and increases bone cell adhesion [31-33]. Previous studies have shown that some kind of novel bioactive glasses and bioceramics containing $\mathrm{Sr}$ or $\mathrm{Mg}$ had an enhanced osteostimulating effect on new bone formation, thus indicating $\mathrm{Sr}^{2+}$ ions may improve the osteogenic activity of silicate ceramics [31, 34-36]. Therefore, it is reasonable to assume that Sr-doping of CSi-Mg may tune its bioactivity, biodegradability, and even mechanical stability.

In this study, we designed $\mathrm{Mg} / \mathrm{Sr}$ co-doped wollastonite (CSi-Mg5Srx) macroporous bioceramics with different concentrations of $\mathrm{Sr}(x=0 \%, 2.5 \%, 5 \%, 10 \%)$, and we investigated the concentration-dependent changes in their biodegradable and mechanical properties in vitro. The porous scaffolds, with a variety of pore geometries, were fabricated using CAD and ceramic stereolithography [37]. The scaffolds were systematically characterized before and after immersion in biomimetic body solution media, such as SBF and Tris- $\mathrm{HCl}$ buffers. Their physiochemical and mechanical properties were evaluated based on pore geometry and Sr dopant content.

\section{Materials and methods}

\section{Chemicals and materials}

The reagent-grade inorganic salts were bought from Sinopharm Reagent Co., Shanghai, and used without further purification. The organic reagents, including 1,6hexanediol diacrylate (HDDA; Alfa Aesar Co.), 6trimethyl- benzoyldiphenylphosphine oxide (TBDPO; BASF (China) Co., LTD), and ethoxylated pentaerythritol tetraacrylate (PPTTA; DSM-AGI Co., LTD) were used directly without any pretreatment. Simulated body fluid (SBF; Kokubo's recipe) was prepared in ultrapure water and buffered to a $\mathrm{pH} \sim 7.40$ before $0.22-\mu \mathrm{m}$-membrane filtering [38]. Trishydroxymethylaminomethane (Tris) was used to prepare the $0.05 \mathrm{M}$ Tris buffer $(\mathrm{pH} \sim 7.40$ ).

\section{Synthesis of CSi-Mg5Srx powders}

The CSi-Mg5Sr $x\left(\mathrm{Ca}_{100-5 \%-x \%} \mathrm{Mg}_{5 \%} \mathrm{Sr}_{x \%} \mathrm{SiO}_{3} ; x=0,2.5\right.$, $5,10)$ powders were synthesized using a wet-chemical precipitation method as previously described [39]. After calcinating at $850{ }^{\circ} \mathrm{C}$ for $2 \mathrm{~h}$ in a muffle furnace with a 
heating rate of $2{ }^{\circ} \mathrm{C} / \mathrm{min}$, the $\mathrm{CSi}-\mathrm{Mg} 5 \mathrm{Sr} x$ powders were ground with zirconia ball grounding media for $6 \mathrm{~h}$. The particle size of the resulting powders was below $5 \mu \mathrm{m}$. The CSi-Mg5Sr $x$ powder was verified by X-ray diffractometry (XRD; Rigaku D/max-rA) using $\mathrm{CuK \alpha}$ radiation at $40 \mathrm{kV} / 40 \mathrm{~mA}$. Data were collected between $10^{\circ}$ and $60^{\circ}$ to identify any crystallization of the powders. The contents of $\mathrm{Ca}, \mathrm{Mg}, \mathrm{Si}$ and $\mathrm{Sr}$ in the powders were measured using inductively coupled plasma-optical emission spectroscopy (ICP-OES: 710-ES, Varian; USA).

\section{D printing of porous scaffolds}

The powder suspensions used for printing contained the following main components: curable monomers, photo initiators, dispersants and $\mathrm{CSi}-\mathrm{Mg} 5 \mathrm{Sr} x$ powders. HDDA and PPTTA were used as the monomers, with a mass ratio (mHDDA: mPPTTA) of 7:1. The volume loading rate of $\mathrm{CSi}-\mathrm{Mg} 5 \mathrm{Sr} x$ powder was approximately $60 \%$. The powders and resins were mixed in a ball mill for $2 \mathrm{~h}$. The wavelength of the stereolithography apparatus used for the curing ultraviolet (UV) light was $405 \mathrm{~nm}$. The cured layer was placed directly on the glass sheet and irradiated with UV light from below. The intensity of decayed UV light above the cured layer was measured with a radiometer. The photosensitive area of the radiometer was an 8-mm-diameter circle. The cured layers were manufactured with a thickness between 50 and $60 \mu \mathrm{m}$.

3D scaffolds with different shapes were designed using Magics software, including Cylindrical, Cubic and Gyroid structures (see Scheme 1). The cell structure of the Gyroid was created using MathMod software and characterized by Magics software, which of the Cylindrical and Cubic were only created and characterized by Magics software. The software of Avizo was used to calculate the average pore size and porosity of cell units to control the porosity and the average pore size of the three structures keeping respectively the same as $~ 58 \%$ and $\sim 600 \mu \mathrm{m}$ during the design stage for the porous scaffold. The corresponding porous scaffold was built by the "Structure" function in the software of Magics based on the cell unit created and authenticated by the above method. Therefore, they had similar sectional pore areas with approximate theoretical porosity. As shown in Scheme 1, the printed bodies were finally obtained by a process of stereolithography in the Autoceram Ceramic 3D Printer (Beijing Ten Dimensions Technology Co., Ltd., China) and based on the photo-polymerization of a

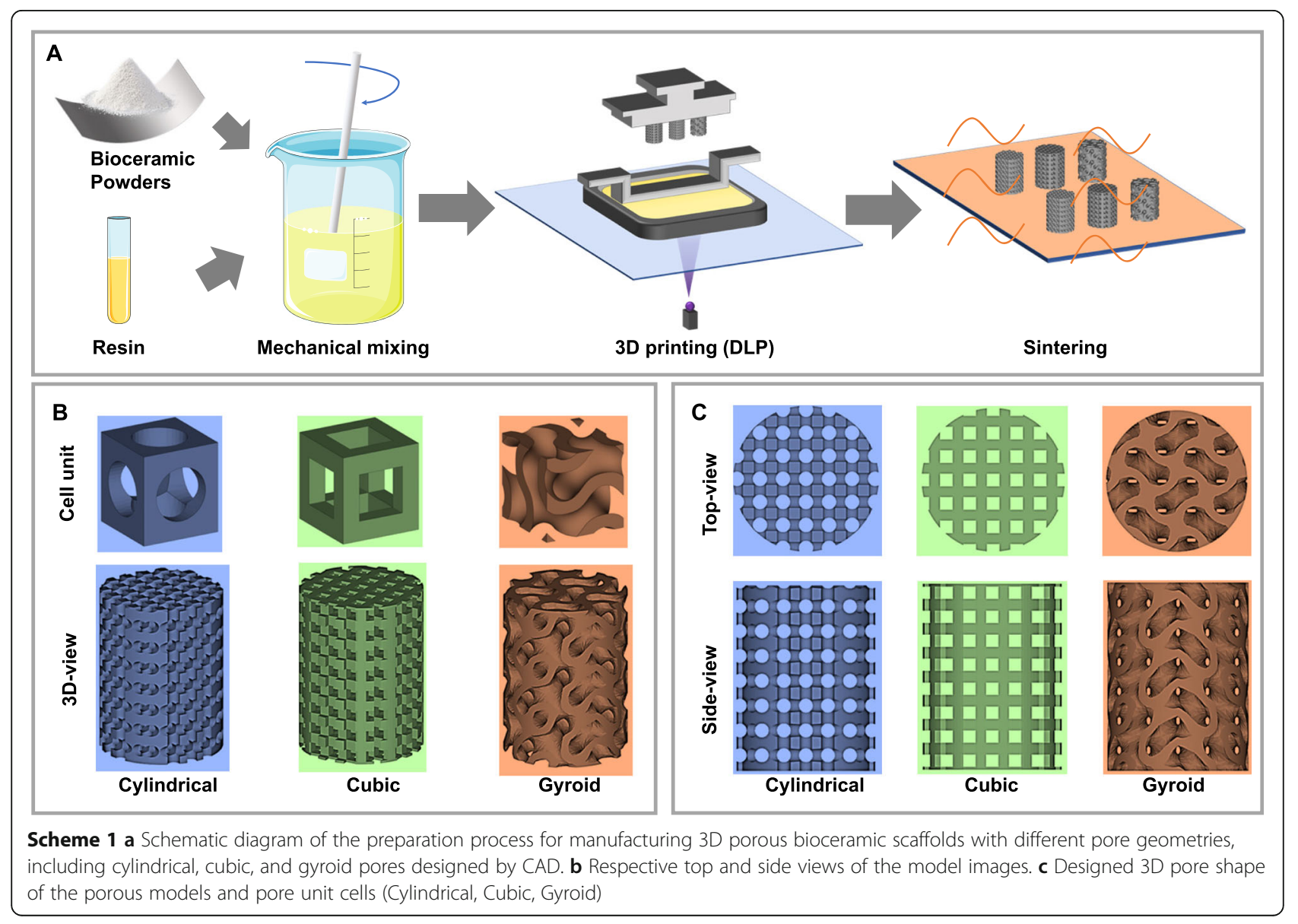


mixture of resins and powders. Every layer was patterned and 3D structure was formed by stacking each layer of flats into the 3D pattern. The powder-resin slurry was poured into the printing tank, and applicable exposure parameters were selected to complete the bottom-up stereolithography process. After the printing process completed, the printed bodies were washed ultrasonically in deionized water, and then dried at $80^{\circ} \mathrm{C}$ overnight. Finally, the porous bodies were sintered in a Muffle furnace at a target temperature of $1150^{\circ} \mathrm{C}$ using similar heating schemes (the heating rate was $3{ }^{\circ} \mathrm{C} / \mathrm{min}$ and $400{ }^{\circ} \mathrm{C}$ was maintained for $120 \mathrm{~min}$ ) and held at the target temperature for $3 \mathrm{~h}$. Afterward, they were allowed to cool naturally.

\section{Primary morphology and structure analysis}

The external scaffold morphology and pore architecture were observed using a mobile camera (iPhone 10, Apple). The surface and fracture microstructures of the bioceramic scaffolds were investigated with scanning electron microscopy (SEM; JEM-6700F; Japan). Prior to examination, the macroporous samples were coated with a thin layer of gold. The linear shrinkage before and after sintering was determined by measuring the diameter and height of the cylindrical scaffolds before and after sintering using a digital sliding caliper.

\section{Porosity analysis}

The suitability of design for the porous scaffolds was determined by the calculated porosity of modeled samples. The volume and pore strut of the porous architecture were taken from Magics 21 software and used to determine the theoretical porosity. Another zero-damage method was used to measure the real porosities of the sintered cylindrical porous scaffolds. The mass $\left(m_{1}\right)$ of the sintered porous scaffolds was measured on a scale, and then the diameter $(D)$ and height $(H)$ were measured by using a Vernier caliper. The real porosity of the scaffolds $(n=6)$ was calculated using the following equation:

$$
\begin{gathered}
\text { Real porosity }=\left(1-V / V_{s}\right) \times 100 \% \\
V=m_{s} / \rho_{0} \\
V_{s}=\pi \times(D / 2)^{2} \times H
\end{gathered}
$$

where $V, \mathrm{~V}_{\mathrm{s}}, m_{s}$, and $\rho_{0}$ were the volume of the solid structure, the volume of the porous sample, the mass of the porous sample, and the density of low dosage of $\mathrm{Mg}$ substituted wollastonite $\left(\rho_{0}=2.917 \mathrm{~g} / \mathrm{cm}^{3}\right)$.

\section{Mechanical testing}

The compressive strengths $\left(\sigma_{\mathrm{c}}\right)$ of the sintered bioceramic scaffolds $(\varnothing 6 \times 8 \mathrm{~mm} ; n=6)$ were tested using a universal testing machine (Instron 5566) and a $10 \mathrm{kN}$ load cell at a crosshead speed of $0.5 \mathrm{~mm} \mathrm{~min}^{-1}$. The young's modulus $\left(E_{c}\right)$ was calculated from the slope of the linear elastic region of the stress-strain curves. The following formula was used for the calculation:

$$
\begin{aligned}
\sigma_{\mathrm{c}} & =F / A \\
E_{c} & =\sigma_{\mathrm{c}} / \varepsilon
\end{aligned}
$$

where $F, A, E, \varepsilon$ are the maximal load $(\mathrm{N})$, the circle surface area perpendicular to the load direction $\left(\mathrm{mm}^{2}\right)$, the compressive modulus $(\mathrm{MPa})$, and the strain $(\mathrm{mm} / \mathrm{mm})$, respectively.

The specific compressive strength $\left(\sigma_{\mathrm{s}}\right)$ and Young's modulus $\left(E_{\mathrm{s}}\right)$ of the sintered scaffolds based on the apparent density $\left(\rho_{s}\right)$, were calculated using the following equation:

$$
\begin{aligned}
\sigma_{s} & =F / S_{s} \\
E_{\mathrm{s}} & =E_{c} / S_{s}
\end{aligned}
$$

The specific compressive strength $\left(\sigma_{d}\right)$ and Young's modulus $\left(E_{d}\right)$ based on the minimum cross-sectional area $\left(S_{s}\right)$ perpendicular to the load direction, were calculated using the following equation:

$$
\begin{gathered}
\sigma_{d}=\sigma_{\mathrm{c}} / \rho_{s} \\
E_{d}=E_{c} / \rho_{s} \\
\rho_{s}=m_{\mathrm{s}} / V_{\mathrm{s}}
\end{gathered}
$$

where $\rho_{\mathrm{s}}$ is calculated by the mass $\left(m_{\mathrm{s}}\right)$ and apparent volume $\left(\mathrm{V}_{\mathrm{s}}\right)$ of the scaffolds, and $S_{s}$ was measured by $\mu \mathrm{CT}$ analysis.

\section{In vitro bio-dissolution evaluation}

The CSi-Mg5Sr10 bioceramic scaffolds, with three types of pore geometries, and the bioceramic scaffolds with increasing $\mathrm{Sr}$ contents $\left(\varnothing 6 \times 8 \mathrm{~mm} ; n=9 ; W_{0}\right)$ were respectively immersed in Tris buffer $(0.05 \mathrm{M}$; pH 7.4; $37^{\circ} \mathrm{C}$ ) at a scaffold/buffer ratio of $1.0 \mathrm{~g} / 50 \mathrm{ml}$ for 8 weeks. The Tris buffer was replaced every 7 days. From $4 \mathrm{~h}$ to 14 days after soaking, the buffer $(0.5 \mathrm{ml})$ was extracted for ICP-OES analysis, and fresh buffer $(0.5 \mathrm{ml})$ was added. After immersion for 2-8 weeks, three scaffolds in each group were rinsed with absolute ethanol, dried, and weighed $(W t)$. The mass decay was calculated with the following formula: Mass Decrease $=W_{t} / W_{O} \times$ $100 \%$. The mechanical strength of the dried scaffolds was also determined with a universal testing machine.

\section{In vitro evaluation of surface re-mineralization}

The porous scaffolds $(\varnothing 6 \times 8 \mathrm{~mm})$ were immersed in $10 \mathrm{ml}$ of simulated body fluid (SBF) with an inorganic ion content similar to that of human plasma $\left(\mathrm{Na}^{+}, 142\right.$ $\mathrm{mM} ; \mathrm{K}^{+}, 5 \mathrm{mM} ; \mathrm{Ca}^{2+}, 2.5 \mathrm{mM} ; \mathrm{Mg}^{2+}, 1.5 \mathrm{mM} ; \mathrm{SO}_{4}{ }^{2-}, 1$ $\mathrm{mM} ; \mathrm{HPO}_{4}{ }^{2-}, 1 \mathrm{mM} ; \mathrm{Cl}^{-}, 36 \mathrm{mM} ; \mathrm{HCO}_{3}{ }^{-}, 14 \mathrm{mM}$ ) [38]. During the immersion, which was done at $37^{\circ} \mathrm{C}$, we 


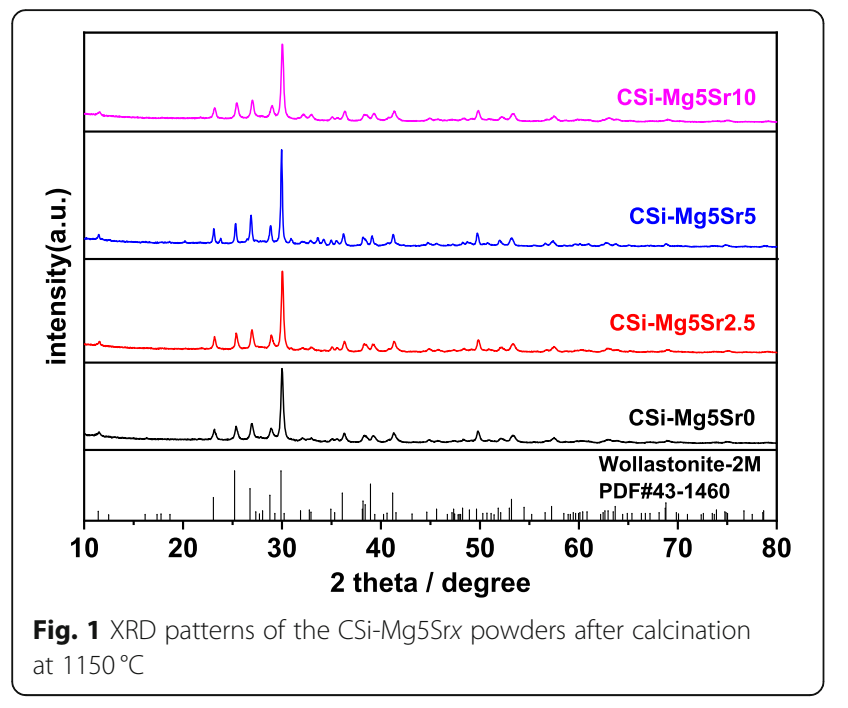

monitored the formation of biomimetic hydroxyapatite (HA) on the surface of the scaffolds. After soaking for 7 days, the scaffolds were washed with distilled water, observed with SEM, chemically analyzed with energy dispersive X-rays (EDX).

\section{Statistical analysis}

The data were expressed as mean \pm standard deviation (SD) and analyzed with one-way ANOVA. In all cases the results were considered statistically significant when the $p$-value was less than 0.05 .

\section{Results}

\section{Primary characterization of the bioceramic scaffolds}

Figure 1 shows the XRD patterns of the CSi-Mg5Srx bioceramic scaffolds. All diffraction peaks for all samples were identified as wollastonite-2 M phase (PDF \#431460 ), suggesting that the Sr-substitution (up to 10\%) led to no phase transformations of the CSi-Mg5. Moreover, the main diffraction peak shifts to higher or lower values due to the doping of $\mathrm{Sr}$ or $\mathrm{Mg}$, indicating that the nonstoichiometric CSi was partly doped by the foreign ions. According to ICP analysis (Table 1), the real values of $\mathrm{Mg}$ or $\mathrm{Sr}$ substitution were similar to the theoretical ones. The Mg content in the $\mathrm{CSi}-\mathrm{Mg} 5 \mathrm{Sr} x(x=0,2.5,5$, 10) powders was $5.51-5.80 \%$, and the Sr contents $(0-$ 9.5\%) were increased with increasing $\mathrm{Sr}$ concentrations in the reaction solutions.

\section{Structural evaluation of bioceramic scaffolds}

The processing parameters and conditions used for the preparation of the porous samples were summarized in Table 2. The linear shrinkage of the sintered CSiMg5Sr $x$ scaffolds displayed a steady increase from 15.5$16.3 \%$ for the CSi-Mg5Sr0 to $24.0-26.0 \%$ for the CSiMg5Sr5, but then decreased to $17.4-18.7 \%$ for the CSiMg5Sr10. It was worth noting, however, that there was no significant difference in shrinkage between the scaffolds with each of the three types of pore geometries. Additionally, as mentioned above, the real porosities were contrary to the fluctuations of linear shrinkage, even though the CAD-based porosities of the CSi$\operatorname{Mg} 5 \operatorname{Sr} x$ scaffolds were similar to each other during the model design.

The outward appearance of scaffolds with precisely defined pore geometries after sintering was observed by digital camera (Fig. 2a). It was clear, from the top and side views, that the nearly cylindrical, cubical, or gyroidcurve pores were maintained. The scaffolds retained their porous architecture with no noticeable deformation of the total structure, except for some degree of shrinkage. Characterization of the sintered pore surface by SEM observation (Fig. 2b) clearly showed significant sintering densification and grain growth.

\section{Mechanical properties}

The apparent compressive strength and Young's modulus of the bioceramic scaffolds were shown in Fig. 3 . Overall, the cylindrical pore scaffolds had the highest compressive strength $(\geq 16 \mathrm{MPa})$. The gyroid-pore CSi$\operatorname{Mg} 5 \mathrm{Sr} x$ scaffolds showed very low strength $(\leq 12 \mathrm{MPa})$, except for the CSi-Mg5Sr5 variant. Interestingly, the cubic pore scaffolds maintained very stable compressive resistance $(\sim 16 \mathrm{MPa})$ until the $\mathrm{Sr}$ substitution was up to $10 \%$ ( $10 \mathrm{MPa}$; Fig. 3a). On the other hand, it was interesting that the apparent Young's modulus of the gyroid pore scaffolds was significantly higher than that of cubic pore scaffolds containing same $\mathrm{Sr}$ content (Fig. $3 \mathrm{~b}$ ). The specific strength and modulus of the scaffolds also showed similar results, which verified this point of view (Fig. 3c-f).

\section{Evaluation of degradation in vitro}

The in vitro biodegradation of the bioceramic scaffolds with different pore geometries or $\mathrm{Sr}$ contents was

Table 1 ICP of different $\mathrm{Sr}$ and $\mathrm{Mg}$ co-doping $\mathrm{CaSiO}_{3}$ scaffolds

\begin{tabular}{|c|c|c|c|c|c|}
\hline Powders & Ca (ppm) & Sr (ppm) & Mg (ppm) & $\mathrm{Sr}(\mathrm{mol} \%)$ & $\mathrm{Mg}(\mathrm{mol} \%)$ \\
\hline CSi-Mg5SrO & 35.205 & 0 & 1.275 & 0 & 5.51 \\
\hline CSi-Mg5Sr2.5 & 39.995 & 2.920 & 1.500 & 3.05 & 5.67 \\
\hline CSi-Mg5Sr5 & 40.155 & 4.610 & 1.570 & 4.71 & 5.80 \\
\hline CSi-Mg5Sr10 & 37.840 & 8.805 & 1.560 & 9.52 & 5.52 \\
\hline
\end{tabular}


Table 2 Structural parameters of the pores in the Mg5Srx scaffolds

\begin{tabular}{|c|c|c|c|c|c|}
\hline Pore geometry & Samples & Side-length/diameter of pore $(\mu \mathrm{m})$ & Shrinkage (\%) & CAD-porosity (\%) & Real porosity (\%) \\
\hline \multirow[t]{4}{*}{ Cylindrical } & CSi-Mg5SrO & D600 & $16.3 \pm 4.2$ & 54.3 & $53.8 \pm 2.9$ \\
\hline & CSi-Mg5Sr2.5 & & $19.5 \pm 0.7$ & & $54.1 \pm 1.4$ \\
\hline & CSi-Mg5Sr5 & & $24.0 \pm 0.8$ & & $50.3 \pm 3.6$ \\
\hline & CSi-Mg5Sr10 & & $18.7 \pm 6.0$ & & $53.1 \pm 2.6$ \\
\hline \multirow[t]{4}{*}{ Cubic } & CSi-Mg5SrO & 600 & $15.5 \pm 1.7$ & 55.2 & $53.5 \pm 1.8$ \\
\hline & CSi-Mg5Sr2.5 & & $21.3 \pm 1.0$ & & $49.0 \pm 2.1$ \\
\hline & CSi-Mg5Sr5 & & $26.0 \pm 2.9$ & & $46.7 \pm 3.5$ \\
\hline & CSi-Mg5Sr10 & & $18.3 \pm 1.1$ & & $57.9 \pm 1.4$ \\
\hline \multirow[t]{4}{*}{ Gyroid } & CSi-Mg5SrO & D600 & $15.9 \pm 0.9$ & 57.2 & $55.9 \pm 0.9$ \\
\hline & CSi-Mg5Sr2.5 & & $18.3 \pm 1.2$ & & $59.2 \pm 1.4$ \\
\hline & CSi-Mg5Sr5 & & $25.2 \pm 0.3$ & & $54.1 \pm 1.8$ \\
\hline & CSi-Mg5Sr10 & & $17.4 \pm 1.4$ & & $55.6 \pm 2.0$ \\
\hline
\end{tabular}

monitored by calculating the ion concentration in Tris buffer. ICP analysis depicted the changes in ion concentration during the scaffold immersions (Fig. 4). As can be seen in Fig. 4a-d, the four types of inorganic ions $(\mathrm{Ca}$, $\mathrm{Mg}, \mathrm{Si}, \mathrm{Sr}$ ) released were directly mediated by the $\mathrm{Sr}$ dopant concentrations. The $\mathrm{Ca}$ and $\mathrm{Mg}$ release rates were promoted and inhibited, respectively, but the Si release rate was not regularly affected by Sr dopant concentrations. However, it was unexpected that the CSiMg5Sr5 scaffolds showed significantly slower ion release

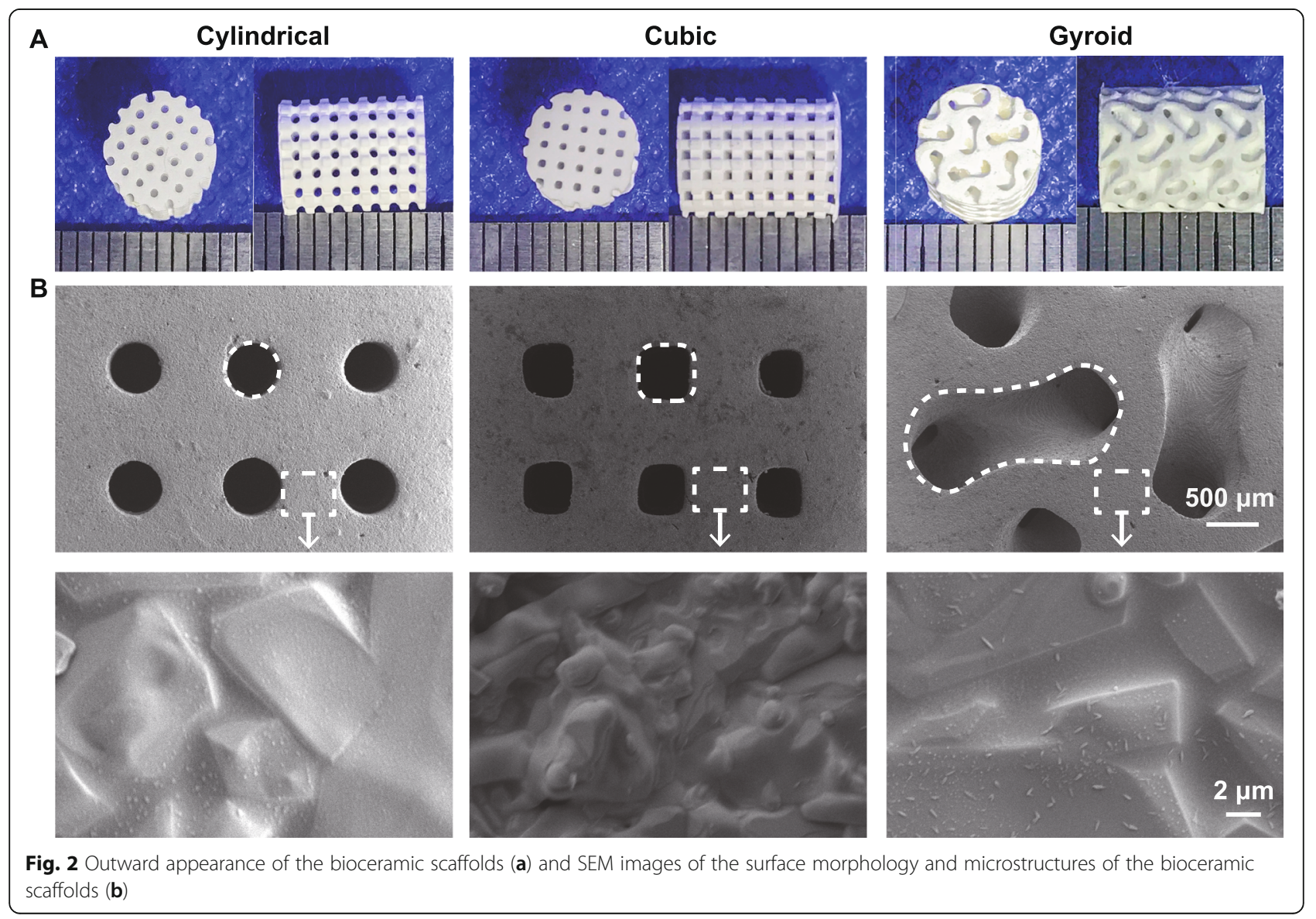




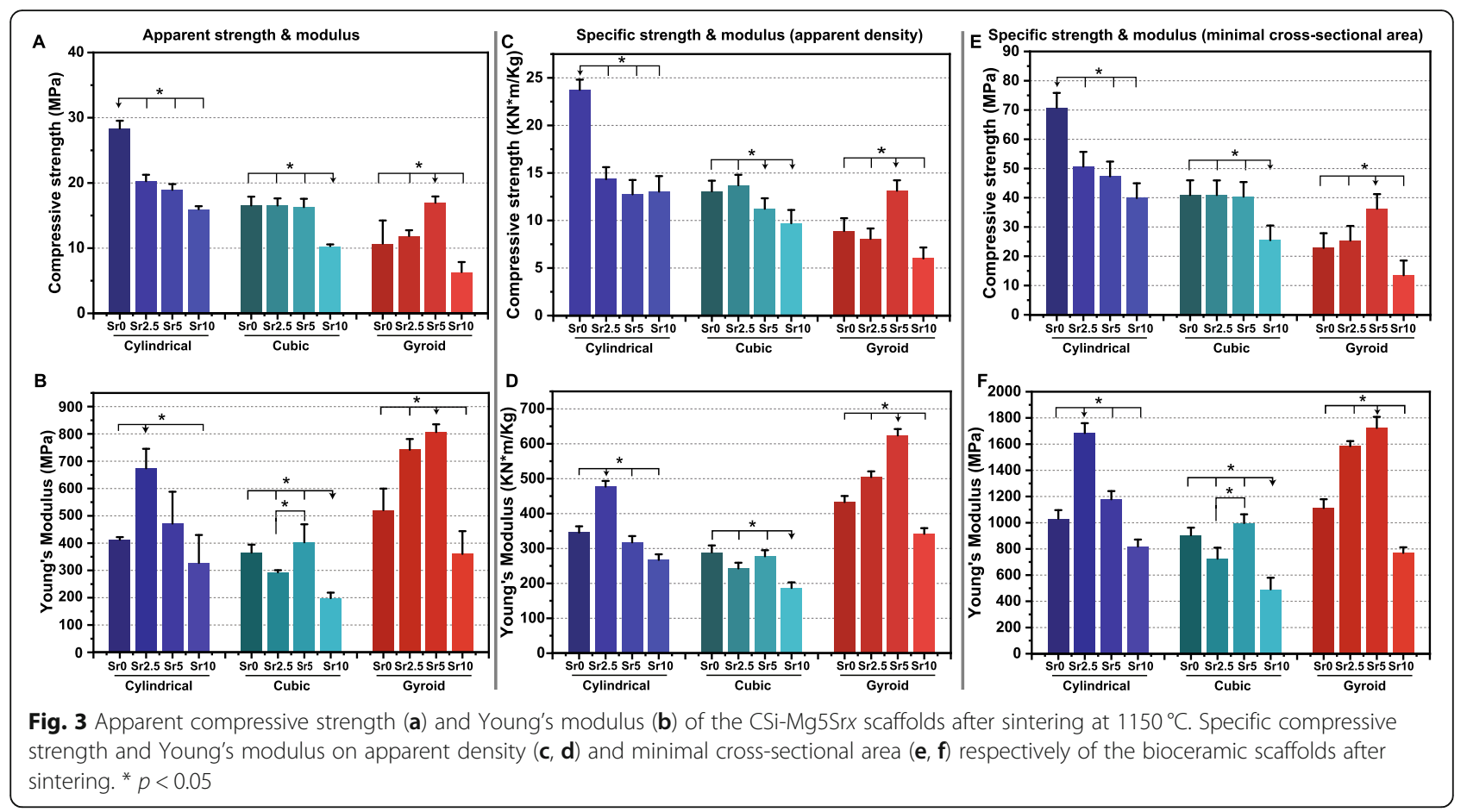

rates for $\mathrm{Ca}, \mathrm{Mg}$ and $\mathrm{Si}$ in the early stages of immersion. Indeed, the higher the $\mathrm{Sr}$ content in the scaffolds, the higher the Sr ion concentration in the Tris buffer.

On the other hand, in Fig. 4e-h, the ions are released quickly within the first $24 \mathrm{~h}$ and then maintain a mild bio-dissolution rate in the buffer with the prolongation of immersion time. It was worth mentioning that, in total, the cubic pore scaffolds of $\mathrm{CSi}-\mathrm{Mg} 5 \mathrm{Sr} 10$ showed appreciable $\mathrm{Ca}, \mathrm{Mg}$, and $\mathrm{Sr}$ release in the early stages of immersion, but the gyroid pore scaffolds released ions slowly during the first 5 days.
The mass decrease of the scaffolds mentioned above was measured during immersing in Tris buffer from 2 to 8 weeks, to simulate the microenvironment in the body (Fig. 5). The Sr-containing CSi-Mg5Srx scaffolds showed more appreciable mass decrease $(\sim 2.5-4.3 \%)$ in comparison with the CSi-Mg5Sr0 ( 1.0\%) scaffolds in the initial 2 weeks (Fig. 5a), implying the bio-dissolution may be accelerated by Sr doping. The CSi-Mg5Sr5 scaffolds were sparingly soluble after 4 weeks but were undergoing rapid biodissolution at 8 weeks ( $~ 8.7 \%$ of mass loss). As expected, the $\mathrm{CSi}-\mathrm{Mg} 5 \mathrm{Sr} 0$ scaffolds were sparingly dissolvable in the
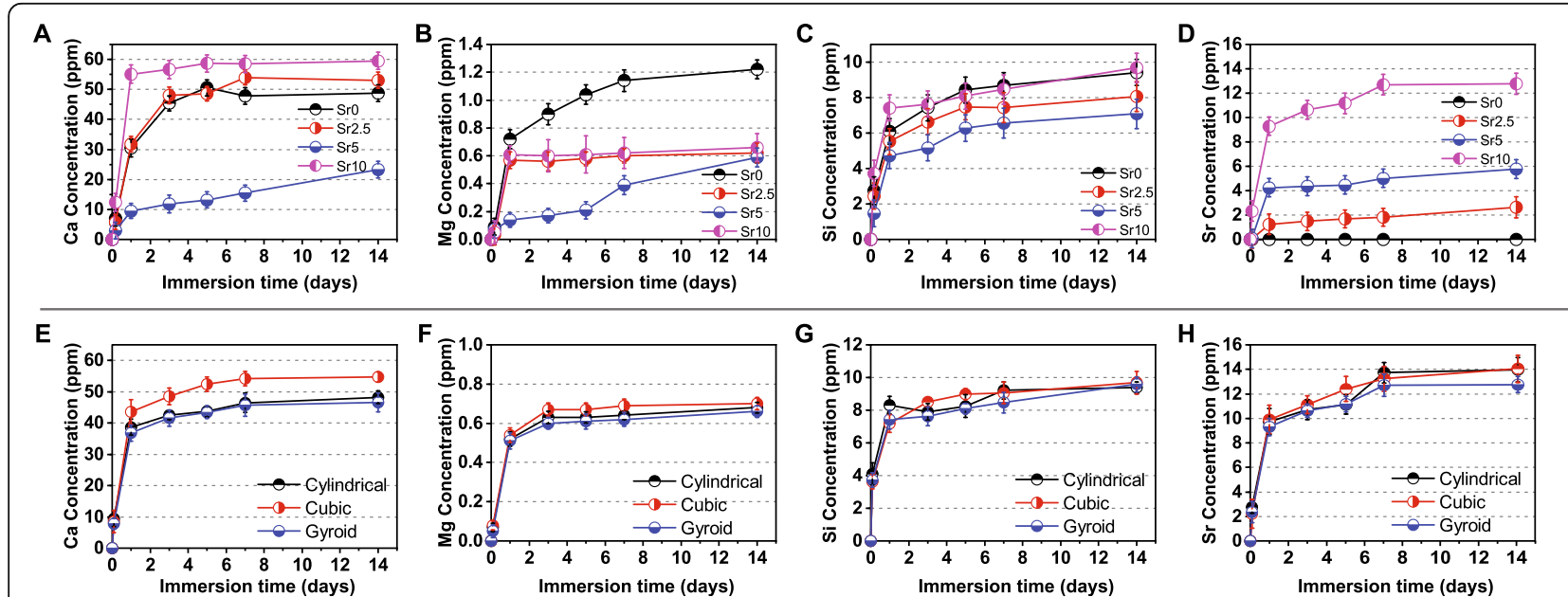

Fig. 4 Bioactive ion release from the CSi-Mg5Srx bioceramic scaffolds with different Sr concentrations (a-d) or different pore geometries (e-h) during immersion in Tris buffer for 14 days 

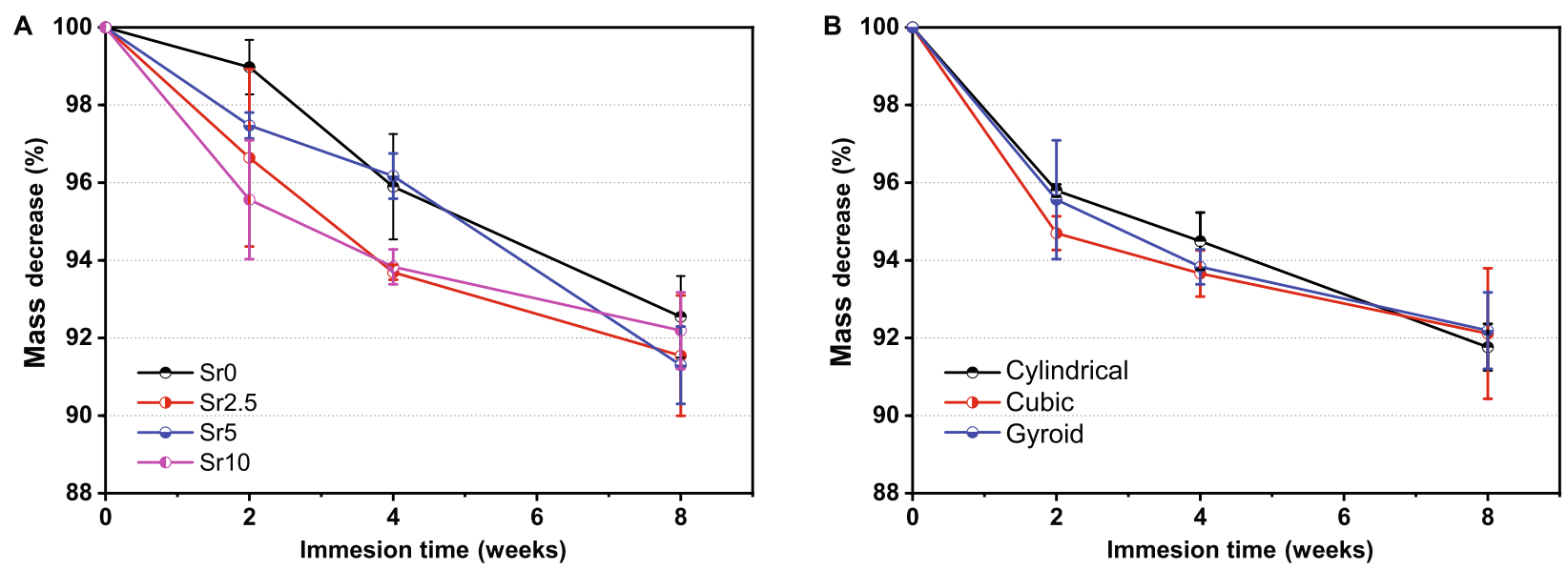

Fig. 5 Mass decrease of the cylindrical CSi-Mg5Srx (a) and Mg5Sr10 (b) bioceramic scaffolds during immersion in Tris buffer for 8 weeks

whole immersion stage. Interestingly, the pore geometries of the CSi-Mg5Sr10 bioceramic scaffolds did not exhibit notable differences in mass decrease (Fig. 5b).

The $\mathrm{pH}$ value in the Tris buffer increased gradually with the prolongation of immersion time, and Sr doping accelerated the process of $\mathrm{pH}$ increase. However, the different pore geometries had no significant effect on the change in $\mathrm{pH}$ value (Fig. 6). Moreover, the difference in the surface morphology of gyroid-pore scaffolds was characterized by SEM observations before and after the 8 -week immersion. It can be seen from Fig. 7 that the pore wall became more noticeable rough and that the densification of the curved pores significantly decreased due to the bio-dissolution of the surface layer of the bioceramic struts.

To further verify the strength decay during the immersion stage in Tris buffer, the compressive strength of bioceramic scaffolds was measured after immersing them for 2-8 weeks. As shown in Fig. 8, the compressive

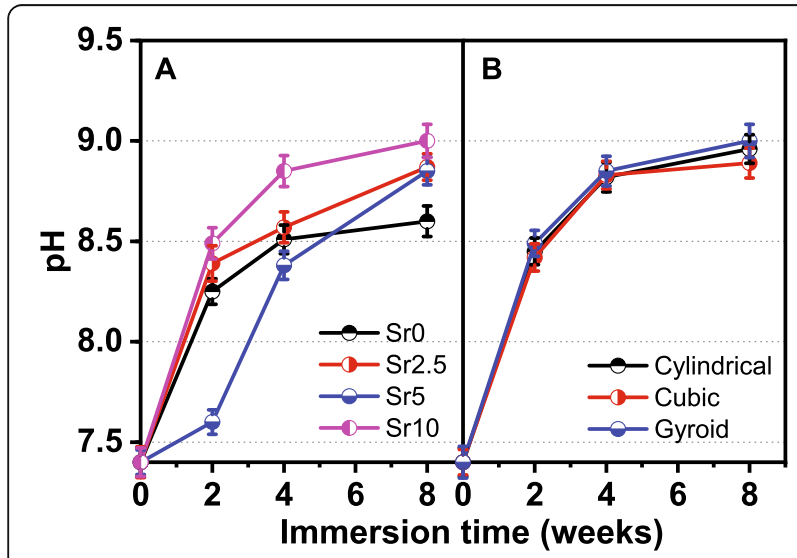

Fig. 6 Changes in $\mathrm{pH}$ value in the Tris buffer during immersion of the CSi-Mg5Srx bioceramic scaffolds with cylindrical pores (a) or composed of Mg5Sr10 (b) strength tended to decrease throughout the whole process. The cylindrical pore $\mathrm{CSi}-\mathrm{Mg} 5 \mathrm{Sr} x$ scaffolds maintained an appreciable compressive strength during the whole period of immersion, and the apparent strength was above $2.5 \mathrm{MPa}$ after immersing for 8 weeks. Indeed, the CSi-Mg5Sr10 scaffolds exhibited structural stability after 8 weeks, though their compressive resistance was significantly lower than the other scaffolds in the whole immersion stage.

\section{Evaluation of surface re-mineralization in vitro}

The surface-inducing apatite re-mineralization bioactivity in vitro was characterized with SEM-EDX analysis. Figure 9 shows the SEM images of the scaffolds after immersing for 14 days in SBF. It can be seen that the pore geometries of the scaffolds were consistent before and after the immersion. Furthermore, it was observed that a dense new precipitate layer was coated onto the surface of the pore wall. According to the quantitative EDX analysis, there were significantly strong $\mathrm{Ca}$ and $\mathrm{P}$ peaks in the precipitate layer and the $\mathrm{Ca} / \mathrm{P}$ ratio for the surface layer was 1.18-1.87. The higher the Sr content in the bioceramic scaffolds, the higher the $\mathrm{Ca} / \mathrm{P}$ ratio. This indicates that an apatite re-mineralization layer may readily deposit onto the pore walls.

\section{Discussion}

It is well known that $\mathrm{Mg}$ ions can stimulate the proliferation and activity of osteogenic cells, inhibit the formation of osteoclasts, and promote angiogenesis [40, 41]. Some studies indicate that $\mathrm{Mg}$ could also enhance the sintering of glass-ceramics and bioceramics $[42,43]$. According to our previous investigations, dilute $\mathrm{Mg}$ doped CSi ceramics, prepared by conventional pressureless sintering, show significantly enhanced mechanical strength and fracture toughness, but decreased biodegradation rates in vitro and in vivo [44-46]. Indeed, it is still a 

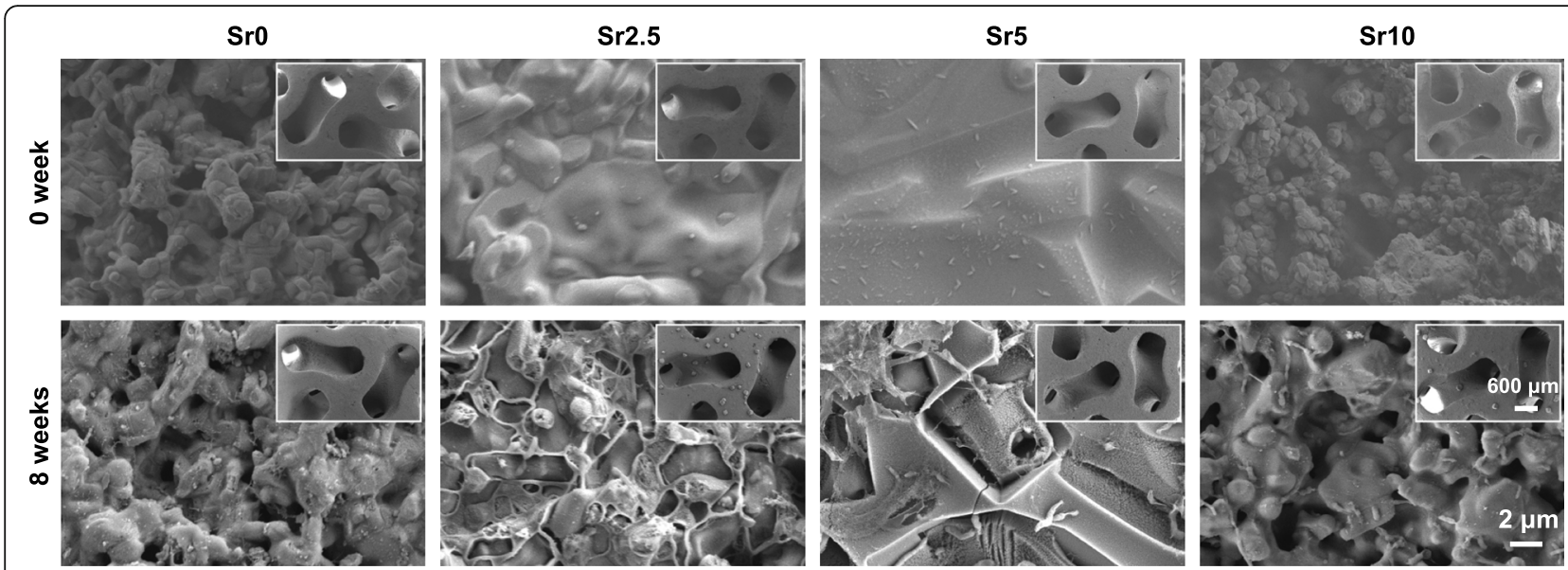

Fig. 7 SEM images of the microstructural surface changes in the pore struts for the gyroid-pore CSi-Mg5Srx scaffolds after immersion in Tris buffer for 8 weeks

challenge to meet the osteogenic capacity and bone repair efficiency in critical-sized bone defects within an expected time window as long as the relationship between the pore structure, geometry, mechanical evolution, bioactivity, and biodegradation behavior of the ceramics is not elucidated. In this regard, we aim to develop $\mathrm{Mg} / \mathrm{Sr}$ co-doped nonstoichiometric CSi scaffolds with appreciable mechanical strength and tunable biodegradation rates. The 3D printed CSi-Mg5Srx scaffolds exhibit wellconnected 3D porous architecture, appropriate pore size, and high porosity, which meet the essential conditions of the new generation of bone tissue-engineering scaffolds $[4,47]$.

It is reported that Sr-doped CSi ceramics have the ability to improve osteogenic differentiation in vitro and in vivo [18], and that $\mathrm{Sr}$ and $\mathrm{Si}$ have synergistic effects on osteoblasts, osteoclasts, and angiogenesis [35]. Previous studies have shown that Sr can also play a rapid role in promoting bone regeneration in the presence of $\mathrm{Ca}$ and $\mathrm{Mg}$ [48]. However, the ion radii of $\mathrm{Sr}$ and $\mathrm{Ca}$ are not the same [49]. Thus, the addition of $\mathrm{Sr}$ into calcium-based bioceramics will affect the stability of the lattice, which will impact the phase-transition temperature, grain geometry, and densification during sintering, which will ultimately affect their mechanical strength [49-51]. The changes to the stability of the lattice will also affect the degradation and ion release kinetics, which may affect the biological activity of the materials [21, 49, 52]. Furthermore, the antiosteoporotic effect of $\mathrm{Sr}$ ions strongly depends on ion dosage, so it is of great significance to study the incorporation of different amounts of $\mathrm{Sr}$ ions into CSiMg bioceramic scaffolds [40].

In this study, we verified the mechanical strength, biodegradability, and other in vitro properties of CSi$\operatorname{Mg} 5 \mathrm{Sr} x$ scaffolds with different pore geometries, to determine the appropriate $\mathrm{Sr}$-substituting concentration, and find a compromise between mechanical properties and biodegradation (including ion release-related bioactivity). XRD and ICP analysis confirmed that the Srsubstituted bioceramics, with corresponding content levels, were successfully prepared, and that all of them were nonstoichiometric $\mathrm{CSi}$, free of second phases. According to previous studies on Ca-silicate systems, $\mathrm{Sr} \leq$
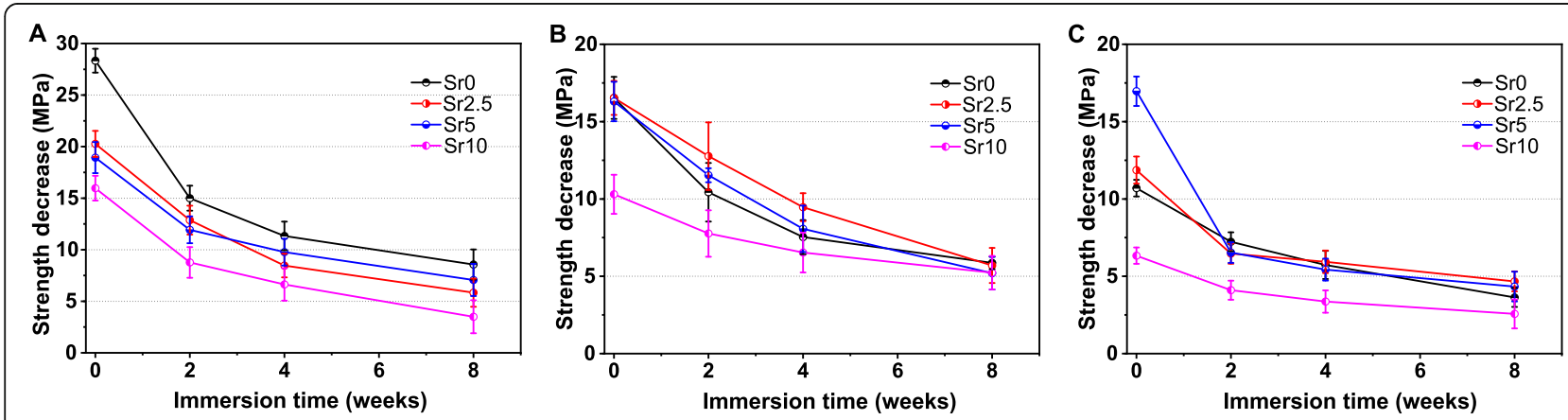

Fig. 8 Strength decrease of the CSi-Mg5Srx bioceramic scaffolds of cylindrical (a), cubic (b), and gyroid (c) pore geometries during the 8-week $\mathrm{HCl}$-Tris buffer immersion 


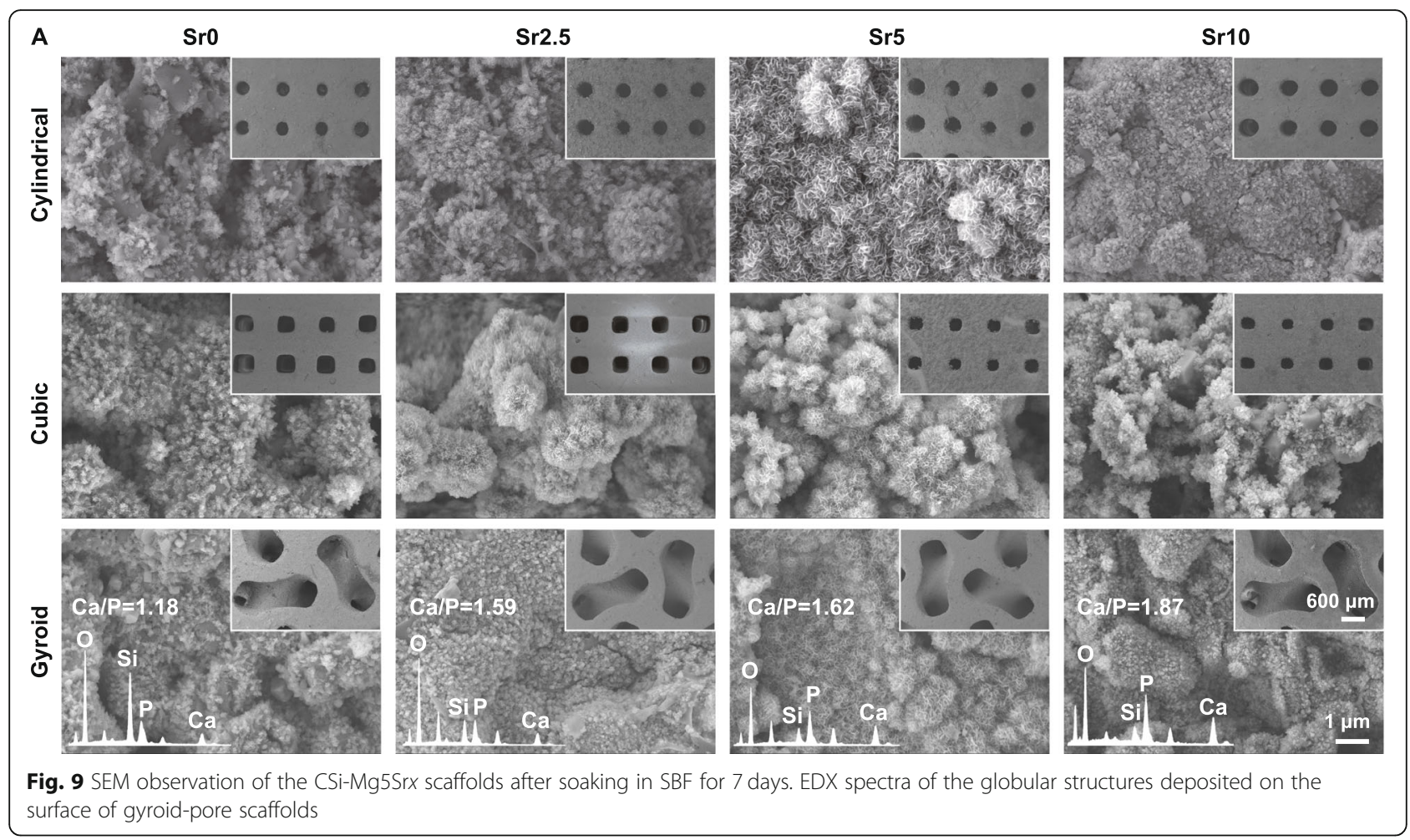

$15 \%$ substitution is necessary to minimize the formation of unwanted second phases that may affect physical, chemical, and biological properties [18, 21, 50]. Because the radius of $\mathrm{Sr}$ ions is different from that of $\mathrm{Ca}$ ions [49], the lattice stability in the CSi bioceramics will be affected. Theoretically, the porous scaffolds containing different $\mathrm{Sr}$ contents need different sintering temperatures to obtain the best densification. In fact, the linear shrinkage and real porosity of the bioceramic scaffolds vary with the increase of Sr content, which may be related to $\mathrm{Sr}$ doping or sintering temperature in the present study [53]. Accordingly, the compactness of porous bioceramic scaffolds is possibly reduced due to high Sr dopant concentrations, and the compressive strength of porous bioceramic scaffolds decreases when Sr substitution is over 5\% [54]. As a result, the compressive strength of CSi-Mg5Sr10 scaffolds is significantly lower than that of the CSi-Mg5Sr0 counterparts, which may be the result of under-sintering. In contrast, we found that the compressive strength of curved pore scaffolds is relatively low under the condition of similar porosity. This just indicates that the curvature and complexity of the pore wall/support have an important influence on the mechanical strength of the bioceramic scaffold. It is worth noting that the Young's modulus of the gyroid pore scaffold is the highest among the three types of scaffolds, which implies that it has the best antideformation ability. Generally speaking, the mechanical strength of porous implants must be within the range of bone mechanical properties to avoid the stress shielding effect or the rapid collapse of the structure [55]. Some $\mathrm{CSi}-\mathrm{Mg} 5 \mathrm{Sr} x$ scaffolds readily meet the requirements necessary to integrate into cancellous bone defect, and thus, are promising in the clinical applications.

As for the biodegradability of bioceramic scaffolds, the results of immersion in Tris buffer were evaluated. First, we confirm that the Sr doping can accelerate the degradation of the bioceramic scaffolds and that this degradation is proportional to the $\mathrm{Sr}$ content level. Interestingly, the co-doping of $\mathrm{Sr}$ ions may accelerate the release rate of $\mathrm{Ca}$ and $\mathrm{Si}$ ions but reduce the release rate of $\mathrm{Mg}$ ions while maintaining the degradation rate of the bioceramics, thus changing the $\mathrm{pH}$ value of the solution. There is a certain correlation between the $\mathrm{Sr}$ release rate and its concentration in scaffolds. In addition, the biodegradation rate of gyroid pore scaffolds is the fastest among the three groups of scaffolds with different pore geometries, which is mainly attributed to its higher specific surface area. This tunable biodegradation rate of the bioceramic scaffolds is thought to be conducive to early osteoblast activity. New bone growth spurred by this bioactivity provides additional benefits, including structural stability and mechanical reliability for bone defect repair [54]. On the other hand, apatite can grow on the pore wall of scaffolds in SBF, which implies that the scaffolds can readily integrate with host bone tissue and produce low inflammatory reactions [38]. As we expect, the biomimetic apatite-like Ca- 
phosphate layer may deposit on the pore wall surface of all scaffolds, demonstrating its ability to induce bone mineral-like inorganic compound growth. Indeed, it may be speculated that the curve surface in the gyroid pore scaffolds is potentially favorable for cell adhesion and growth. Therefore, we believe that the ceramic stereolithography technique is very promising since optimization of the pore geometry is under investigation and promises to yield more intriguing properties.

\section{Conclusion}

In summary, four groups of $\mathrm{CSi}-\mathrm{Mg} 5 \mathrm{Sr} x$ bioceramic powders with different $\mathrm{Sr}$ contents were successfully prepared. They were used in ceramic stereolithography to fabricate porous scaffolds with three types of pore geometries. A suitable concentration of $\mathrm{Sr}$ dopant can be applied to adjust the physicochemical and mechanical properties of $\mathrm{CSiMg} 5$ bioceramic. $\mathrm{Sr}$ can gently promote biodegradation in vitro and has appreciable bioactivity, though its use leads to a minor decline in compressive strength. The studies herein show that the mechanical strength and Young's modulus of the bioceramic scaffolds are directly related to the curved surface-based (gyroid) and strut-based (cylindrical, cubic) pore topologies, and that the gyroid pore scaffolds have higher elastic moduli. Future work may concentrate on the earlystage bone repair efficacy of these foreign ion co-doped bioceramic scaffolds with different pore architectures, which are readily fabricated via stereolithography. Additionally, we recommend the use of this AM technique to develop a variety of high-strength bioceramic scaffolds with precisely tuned pore structures. Their use will lead to more efficient treatments of load-bearing large segmental bone defects in the nearby future, especially from the point of view of osteoporotic or pathological fracture conditions.

\section{Abbreviations \\ CSi: $\mathrm{CaSiO}_{3}$, Wollastonite; Sr: Strontium; Mg: Magnesium; Ca: Calcium; SBF: Simulated Body Fluid; 3D: Three-dimensional; CAD: Computer-aided design}

\section{Acknowledgments}

Not applicable.

\section{Authors' contributions}

$Y L$ performed most of the experiments and wrote the manuscript; RW and MS performed some experiments; LY and XD provided the discussion. FL and $M L$ provided the discussion and materials. $X Y$ wrote and edited the manuscript; ZG and SX conceived the presented idea, designed experiments, wrote research grant and edited the manuscript. All authors read and approved the final manuscript.

\section{Funding}

The authors would like to acknowledge the financial support from the National Key Research and Development Program of China (2017YFE0117700), the National Natural Science Foundation of China (81772311), the Science and Technology Department of Zhejiang Province Foundation (LGF21H060006, LGF20H140008), the Natural Science Foundation of Zhejiang Province (LQ20H060008) and the Zhejiang Medicine and Hygiene Research Program (2018KY055).

\section{Availability of data and materials}

The datasets used and/or analyzed during the current study are available from the corresponding author on reasonable request.

\section{Ethics approval and consent to participate}

This manuscript doesn't report on or involve the use of any animal or human data or tissue so that this section is not applicable.

\section{Consent for publication}

This manuscript contains no details, or videos relating to an individual person so that this section is not applicable.

\section{Competing interests}

The authors declare that they have no competing interests.

\section{Author details}

'Department of Orthopedics, the First Affiliated Hospital, Zhejiang University School of Medicine, \#79 Qingchun Road, Hangzhou, Zhejiang Province 310003, P. R. China. ${ }^{2}$ Operation Room, the First Affiliated Hospital, Zhejiang University School of Medicine, \#79 Qingchun Road, Hangzhou 310003, Zhejiang Province, P. R. China. ${ }^{3}$ Bio-nanomaterials and Regenerative Medicine Research Division, Zhejiang-California International Nanosystem Institute, Zhejiang University, \#866 Yuhangtang Road, Hangzhou, Zhejiang Province 310058, P. R. China.

Received: 29 September 2020 Accepted: 3 December 2020

Published online: 06 January 2021

\section{References}

1. Wen $Y$, Xun S, Haoye M, Baichuan S, Peng C, Xuejian L, Kaihong Z, Xuan Y, Jiang P, Shibi L. 3D printed porous ceramic scaffolds for bone tissue engineering: a review. Biomater Sci. 2017;5(9):1690-8.

2. Yu W, Li R, Long J, Chen P, Hou A, Li L, Sun X, Zheng G, Meng H, Wang Y, Wang A, Sui X, Guo Q, Tao S, Peng J, Qin L, Lu S, Lai Y. Use of a threedimensional printed polylactide-coglycolide/tricalcium phosphate composite scaffold incorporating magnesium powder to enhance bone defect repair in rabbits. J Orthop Translat. 2019;16:62-70.

3. Giannoudis PV, Dinopoulos H, Tsiridis E. Bone substitutes: an update. Injury. 2005;36(Suppl 3):S20-7.

4. Hench LL, Polak JM. Third-generation biomedical materials. Science. 2002; 295(5557):1014-7

5. Moreno Madrid AP, Vrech SM, Sanchez MA, Rodriguez AP. Advances in additive manufacturing for bone tissue engineering scaffolds. Mater Sci Eng C Mater Biol Appl. 2019:100:631-44.

6. Brunello G, Sivolella S, Meneghello R, Ferroni L, Gardin C, Piattelli A, Zavan B, Bressan E. Powder-based 3D printing for bone tissue engineering. Biotechnol Adv. 2016;34(5):740-53.

7. Kumar A, Nune KC, Misra RD. Biological functionality of extracellular matrixornamented three-dimensional printed hydroxyapatite scaffolds. J Biomed Mater Res A. 2016;104(6):1343-51.

8. Bose S, Vahabzadeh S, Bandyopadhyay A. Bone tissue engineering using 3D printing. Mater Today. 2013;16(12):496-504.

9. Butscher A, Bohner M, Hofmann S, Gauckler L, Muller R. Structural and material approaches to bone tissue engineering in powder-based threedimensional printing. Acta Biomater. 2011:7(3):907-20.

10. Lee J, Park J-H, Park M-J, Chung C-W, Min J-K. An intelligent query processing for distributed ontologies. J Syst Softw. 2010;83(1):85-95.

11. Loh QL, Choong C. Three-dimensional scaffolds for tissue engineering applications: role of porosity and pore size. Tissue Eng Part B Rev. 2013; 19(6):485-502.

12. Choi SW, Zhang Y, Xia Y. Three-dimensional scaffolds for tissue engineering: the importance of uniformity in pore size and structure. Langmuir. 2010; 26(24):19001-6.

13. Mou P, Peng H, Zhou L, Li L, Li H, Huang Q. A novel composite scaffold of cu-doped nano calcium-deficient hydroxyapatite/multi-(amino acid) copolymer for bone tissue regeneration. Int J Nanomedicine. 2019;14: 3331-43. 
14. Cooke MN, Fisher JP, Dean D, Rimnac C, Mikos AG. Use of stereolithography to manufacture critical-sized 3D biodegradable scaffolds for bone ingrowth. J Biomed Mater Res B Appl Biomater. 2003;64(2):65-9.

15. Melchels FP, Feijen J, Grijpma DW. A review on stereolithography and its applications in biomedical engineering. Biomaterials. 2010;31(24):6121-30.

16. Williams JM, Adewunmi A, Schek RM, Flanagan $\mathrm{CL}$, Krebsbach PH, Feinberg SE, Hollister SJ, Das S. Bone tissue engineering using polycaprolactone scaffolds fabricated via selective laser sintering. Biomaterials. 2005;26(23): 4817-27.

17. Shen JH, Yang XY, Wu RH, Shen MD, Lu FL, Zhang F, Chen Z, Chen XY, Xu SZ, Gao CY, Gou ZR. Direct ink writing core-shell Wollastonite@Diopside scaffolds with tailorable shell micropores favorable for optimizing physicochemical and biodegradation properties. J Eur Ceram Soc. 2020;40(2):503-12.

18. Lin K, Xia L, Li H, Jiang X, Pan H, Xu Y, Lu WW, Zhang Z, Chang J. Enhanced osteoporotic bone regeneration by strontium-substituted calcium silicate bioactive ceramics. Biomaterials. 2013;34(38):10028-42.

19. Wu C, Chang J. A review of bioactive silicate ceramics. Biomed Mater. 2013: 8(3):032001.

20. Wang GC, Lu ZF, Dwarte D, Zreiqat H. Porous scaffolds with tailored reactivity modulate in-vitro osteoblast responses. Mat Sci Eng C-Mater. 2012; 32(7):1818-26

21. Ni S, Chang J. In vitro degradation, bioactivity, and cytocompatibility of calcium silicate, dimagnesium silicate, and tricalcium phosphate bioceramics. J Biomater Appl. 2009;24(2):139-58.

22. No YJ, Li JJ, Zreiqat H. Doped calcium silicate ceramics: a new class of candidates for synthetic bone substitutes. Materials (Basel). 2017;10(2):153.

23. Mao L, Xia L, Chang J, Liu J, Jiang L, Wu C, Fang B. The synergistic effects of Sr and Si bioactive ions on osteogenesis, osteoclastogenesis and angiogenesis for osteoporotic bone regeneration. Acta Biomater. 2017;61:217-32.

24. Zreiqat H, Ramaswamy Y, Wu C, Paschalidis A, Lu Z, James B, Birke O, McDonald M, Little D, Dunstan CR. The incorporation of strontium and zinc into a calcium-silicon ceramic for bone tissue engineering. Biomaterials. 2010;31(12):3175-84.

25. limori Y, Kameshima Y, Okada K, Hayashi S. Comparative study of apatite formation on $\mathrm{CaSiO} 3$ ceramics in simulated body fluids with different carbonate concentrations. J Mater Sci Mater Med. 2005;16(1):73-9.

26. No YJ, Roohaniesfahani S, Lu Z, Shi J, Zreiqat H. Strontium-doped calcium silicate bioceramic with enhanced in vitro osteogenic properties. Biomed Mater. 2017;12(3):035003.

27. Neves N, Linhares D, Costa G, Ribeiro CC, Barbosa MA. In vivo and clinical application of strontium-enriched biomaterials for bone regeneration: a systematic review. Bone Joint Res. 2017;6(6):366-75.

28. Pemmer B, Roschger A, Wastl A, Hofstaetter JG, Wobrauschek P, Simon R, Thaler HW, Roschger $\mathrm{P}$, Klaushofer K, Streli C. Spatial distribution of the trace elements zinc, strontium and lead in human bone tissue. Bone. 2013;57(1): 184-93

29. Quade M, Schumacher M, Bernhardt A, Lode A, Kampschulte M, Voss A, Simon P, Uckermann O, Kirsch M, Gelinsky M. Strontium-modification of porous scaffolds from mineralized collagen for potential use in bone defect therapy. Mater Sci Eng C Mater Biol Appl. 2018;84:159-67.

30. Rohnke M, Pfitzenreuter S, Mogwitz B, Henss A, Thomas J, Bieberstein D, Gemming T, Otto SK, Ray S, Schumacher M, Gelinsky M, Alt V. Strontium release from $\mathrm{Sr}(2+)$-loaded bone cements and dispersion in healthy and osteoporotic rat bone. J Control Release. 2017;262:159-69.

31. Bellucci D, Cannillo V, Anesi A, Salvatori R, Chiarini L, Manfredini T, Zaffe D. Bone regeneration by novel bioactive glasses containing strontium and/or magnesium: a preliminary in-vivo study. Materials (Basel). 2018;11(11):2223.

32. Zhao R, Chen S, Zhao W, Yang L, Yuan B, Ioan VS, Iulian AV, Yang X, Zhu X, Zhang $X$. A bioceramic scaffold composed of strontium-doped threedimensional hydroxyapatite whiskers for enhanced bone regeneration in osteoporotic defects. Theranostics. 2020;10(4):1572-89.

33. Weng L, Boda SK, Teusink MJ, Shuler FD, Li X, Xie J. Binary doping of strontium and copper enhancing Osteogenesis and angiogenesis of bioactive glass Nanofibers while suppressing osteoclast activity. ACS Appl Mater Interfaces. 2017;9(29):24484-96.

34. Wang S, Liu L, Zhou X, Yang D, Shi Z, Hao Y. Effect of strontium-containing on the properties of mg-doped wollastonite bioceramic scaffolds. Biomed Eng Online. 2019;18(1):119.

35. Diba M, Goudouri OM, Tapia F, Boccaccini AR. Magnesium-containing bioactive polycrystalline silicate-based ceramics and glass-ceramics for biomedical applications. Curr Opin Solid St M. 2014;18(3):147-67.
36. Bose S, Fielding G, Tarafder S, Bandyopadhyay A. Understanding of dopantinduced osteogenesis and angiogenesis in calcium phosphate ceramics. Trends Biotechnol. 2013;31(10):594-605.

37. Abueidda DW, Elhebeary M, Shiang C-S, Pang S, Abu Al-Rub RK, Jasiuk IM. Mechanical properties of 3D printed polymeric Gyroid cellular structures: experimental and finite element study, materials \& design 165; 2019.

38. Kokubo T, Takadama H. How useful is SBF in predicting in vivo bone bioactivity? Biomaterials. 2006;27(15):2907-15.

39. Xie J, Yang X, Shao H, Ye J, He Y, Fu J, Gao C, Gou Z. Simultaneous mechanical property and biodegradation improvement of wollastonite bioceramic through magnesium dilute doping. J Mech Behav Biomed Mater. 2016;54:60-71.

40. Meininger S, Moseke C, Spatz K, Marz E, Blum C, Ewald A, Vorndran E. Effect of strontium substitution on the material properties and osteogenic potential of 3D powder printed magnesium phosphate scaffolds. Mater Sci Eng C Mater Biol Appl. 2019;98:1145-58.

41. Ostrowski N, Lee B, Hong D, Enick PN, Roy A, Kumta PN. Synthesis, Osteoblast, and Osteoclast Viability of Amorphous and Crystalline TriMagnesium Phosphate. ACS Biomater Sci Eng. 2014;1(1):52-63.

42. Bellucci D, Sola A, Salvatori R, Anesi A, Chiarini L, Cannillo V. Role of magnesium oxide and strontium oxide as modifiers in silicate-based bioactive glasses: effects on thermal behaviour, mechanical properties and in-vitro bioactivity. Mater Sci Eng C Mater Biol Appl. 2017;72:566-75.

43. He D, Zhuang C, Xu S, Ke X, Yang X, Zhang L, Yang G, Chen X, Mou X, Liu A, Gou Z. 3D printing of mg-substituted wollastonite reinforcing diopside porous bioceramics with enhanced mechanical and biological performances. Bioact Mater. 2016;1(1):85-92.

44. Shao H, Liu A, Ke X, Sun M, He Y, Yang X, Fu J, Zhang L, Yang G, Liu Y, Xu S, Gou Z. 3D robocasting magnesium-doped wollastonite/TCP bioceramic scaffolds with improved bone regeneration capacity in critical sized calvarial defects. J Mater Chem B. 2017:5(16):2941-51.

45. Sun M, Liu A, Shao H, Yang X, Ma C, Yan S, Liu Y, He Y, Gou Z. Systematical evaluation of mechanically strong 3D printed diluted magnesium doping Wollastonite scaffolds on Osteogenic capacity in rabbit Calvarial defects, scientific reports 6; 2016

46. Xie JJ, Shao HF, He DS, Yang XY, Yao CL, Ye J, He Y, Fu JZ, Gou ZR. Ultrahigh strength of three-dimensional printed diluted magnesium doping wollastonite porous scaffolds. Mrs Communications. 2015;5(4):631-9.

47. Matassi F, Nistri L, Chicon Paez D, Innocenti M. New biomaterials for bone regeneration. Clin Cases Miner Bone Metab. 2011;8(1):21-4.

48. Zhang W, Tian Y, He H, Chen R, Ma Y, Guo H, Yuan Y, Liu C. Strontium attenuates rhBMP-2-induced osteogenic differentiation via formation of SrrhBMP-2 complex and suppression of Smad-dependent signaling pathway. Acta Biomater. 2016:33:290-300.

49. Wu C, Ramaswamy $Y$, Kwik D, Zreiqat $H$. The effect of strontium incorporation into $\mathrm{CaSiO} 3$ ceramics on their physical and biological properties. Biomaterials. 2007;28(21):3171-81.

50. Schumacher TC, Aminian A, Volkmann E, Luhrs H, Zimnik D, Pede D, Wosniok W, Treccani L, Rezwan K. Synthesis and mechanical evaluation of Sr-doped calcium-zirconium-silicate (baghdadite) and its impact on osteoblast cell proliferation and ALP activity. Biomed Mater. 2015;10(5): 055013.

51. Bandyopadhyay A, Petersen J, Fielding G, Banerjee S, Bose S. ZnO, SiO2, and SrO doping in resorbable tricalcium phosphates: influence on strength degradation, mechanical properties, and in vitro bone-cell material interactions. J Biomed Mater Res B Appl Biomater. 2012;100(8):2203-12.

52. Pan HB, Li ZY, Lam WM, Wong JC, Darvell BW, Luk KD, Lu WW. Solubility of strontium-substituted apatite by solid titration. Acta Biomater. 2009;5(5): 1678-85.

53. Manu KM, Karthik C, Ubic R, Sebastian MT, Chen XM. Effect of Ca2+ substitution on the structure, microstructure, and microwave dielectric properties of Sr2Al2SiO7Ceramic. J Am Ceram Soc. 2013;96(12):3842-8.

54. Denry I, Goudouri OM, Fredericks DC, Akkouch A, Acevedo MR, Holloway JA. Strontium-releasing fluorapatite glass-ceramic scaffolds: structural characterization and in vivo performance. Acta Biomater. 2018;75:463-71.

55. Hench LL. Challenges for bioceramics in the 21st century. Am Ceram Soc Bull. 2005;84(9):18-21.

\section{Publisher's Note}

Springer Nature remains neutral with regard to jurisdictional claims in published maps and institutional affiliations. 